\title{
Originals
}

\section{Glucose and Free Fatty Acid Turnover in Normal Subjects and in Diabetic Patients before and after Insulin Treatment}

\author{
Susan E. H. Hall ${ }^{1}$, J. Saunders, and P. H. Sönksen \\ Department of Medicine, St. Thomas's Hospital Medical School, London, England
}

Summary. Turnover rates of glucose and free fatty acids were measured, using ${ }^{3} \mathrm{H}$-glucose and ${ }^{14} \mathrm{C}-1$-palmitic acid as tracers, in insulin-requiring diabetic patients at presentation and after insulin treatment. Correlations were sought with rates of substrate oxidation, determined independently from respiratory exchange, and with plasma hormone concentrations. The rates of appearance of glucose and of free fatty acids were increased in the diabetics to 17.6 and 10.2 $\mu \mathrm{mol} \mathrm{min}{ }^{-1} \mathrm{~kg}^{-1}$ respectively. Both rates fell to normal (13.3 and $7.1 \mu \mathrm{mol} \mathrm{min}{ }^{-1} \mathrm{~kg}^{-1}$ ) after insulin. In the untreated state there was an inverse relationship between the rates of utilisation of glucose and free fatty acids $(r=0.61 ; p<0.05)$. It is suggested that this relationship represents the impairment of peripheral glucose utilisation by free fatty acids and by ketone bodies in vivo, so far only demonstrated in vitro. The tracer calculated rates of glucose utilisation correlated well over a wide range with the respiratory quotient in untreated diabetics, while respiratory quotient was inversely related to free fatty acid turnover rates. In untreated diabetics plasma cortisol and 3,3', 5'-triiodothyronine $\left(\mathrm{rT}_{3}\right)$ were increased whereas thyroxine and 3,5,3'triiodothyronine $\left(T_{3}\right)$ were decreased. $3,5,3^{\prime}-$ Triiodothyronine concentration was closely related to the metabolic clearance rate of glucose $(p<0.05)$, while cortisol concentrations correlated with glucose production $(\mathrm{p}<0.02)$ and blood ketone body concentration $(\mathrm{p}<0.02)$.

It is concluded that glucose overproduction is the major contributor to the hyperglycaemia of untreated diabetes.

1 Present address: Division of Metabolism and Endocrinology, Ottawa Civic Hospital, Ottawa, Ontario, Canada
Key words: Glucose, free fatty acids, oxygen consumption, respiratory quotient, insulin, cortisol, triiodothyronine, thyroxine, ketone bodies, energy balance, insulin-dependent diabetes.

Homeostatic mechanisms normally match the rates of production and utilisation of the two major energy substrates, glucose and free fatty acids (FFA), to the body's immediate requirements. Excess substrate is stored for later use. While plasma FFA concentration may vary in changing physiological circumstances, plasma glucose concentration is controlled rigidly. In diabetes mellitus, insulin deficiency upsets this finely regulated system. A catabolic state results with potential energy wasted as glycosuria. This can be reversed with exogenously administered insulin. In this study, we have investigated the quantitative changes in glucose and FFA kinetics in diabetes and their changes on treatment.

Using two isotopes, rates of production and utilisation of glucose and FFA were measured simultaneously in diabetic patients and compared with values from normal controls.

An estimate of FFA oxidation was obtained from isotopic data. The respiratory quotient (RQ) was measured for comparison as an independent estimate of total energy balance. The effects of insulin treatment on these variables was examined.

Finally the association between the measured variables and insulin, growth hormone, cortisol and thyroid hormones was studied as all these hormones are known to be involved in the regulation of fat and glucose metabolism. 
Table $1 \mathrm{~A}$ and B. Clinical details

A Normal subjects

\begin{tabular}{|c|c|c|c|c|c|c|}
\hline \multirow[t]{2}{*}{ Subject } & \multirow[t]{2}{*}{ Sex } & \multirow[t]{2}{*}{$\begin{array}{l}\text { Age } \\
\text { (years) }\end{array}$} & \multicolumn{2}{|c|}{ Wt $(\mathrm{kg})$} & \multicolumn{2}{|c|}{$\begin{array}{l}\% \text { ideal body } \\
\text { weight }\end{array}$} \\
\hline & & & 1 & $\frac{1}{2}$ & 1 & $\overline{2}$ \\
\hline 1 & $\mathbf{M}$ & 40 & 87 & 86 & 100 & 99 \\
\hline 2 & $\mathbf{M}$ & 30 & 69 & 69 & 98 & 98 \\
\hline 3 & $\mathrm{~F}$ & 56 & 78 & - & 128 & - \\
\hline 4 & $\mathrm{M}$ & 36 & 81 & 82 & 114 & 115 \\
\hline 5 & $\mathbf{F}$ & 41 & 57 & 58 & 90 & 92 \\
\hline 6 & M & 29 & 94 & - & 132 & - \\
\hline 7 & $\mathrm{~F}$ & 41 & 61 & - & 97 & - \\
\hline 8 & $\mathrm{~F}$ & 35 & 66 & - & 108 & - \\
\hline 9 & $\mathbf{M}$ & 60 & 63 & - & 94 & - \\
\hline 10 & $\mathrm{~F}$ & 33 & 59 & - & 94 & - \\
\hline 11 & $\mathrm{M}$ & 21 & 60 & 61 & 104 & 106 \\
\hline 12 & $\mathbf{M}$ & 43 & 75 & 74 & 105 & 104 \\
\hline 13 & $\mathrm{~F}$ & 25 & 60 & 62 & 95 & 98 \\
\hline $\begin{array}{l}\text { Mean } \\
\pm \text { SEM }\end{array}$ & & $38 \pm 3$ & $70 \pm 3$ & $70 \pm 4$ & $105 \pm 4$ & $102 \pm 3$ \\
\hline
\end{tabular}

\section{Methods}

Subjects: Studies were carried out on:

1. Thirteen normal subjects. None had a family history of diabetes. None were receiving medication or suffering from disease. Seven were investigated on a second occasion to assess the normal variation between studies.

2. Thirteen insulin-requiring diabetic patients. None had received previous insulin treatment. The length of history varied from ten days to two years and in eight patients it was less than two months. Five patients had been treated with oral hypoglycaemic agents which were discontinued at least 48 hours before the first test. Twelve were re-studied after diabetic control was established on Actrapid and/or Rapitard insulin (Novo Industri A/S, Copenhagen, Denmark).

Further details of subjects are shown in Table 1

\section{Procedure}

Informed, written consent was obtained from all subjects. All studies were made after a 10 to $12 \mathrm{~h}$ overnight fast with subjects warm, relaxed and semi-supine. Treated diabetics omitted their insulin on the morning of the second test. After cannulation of an

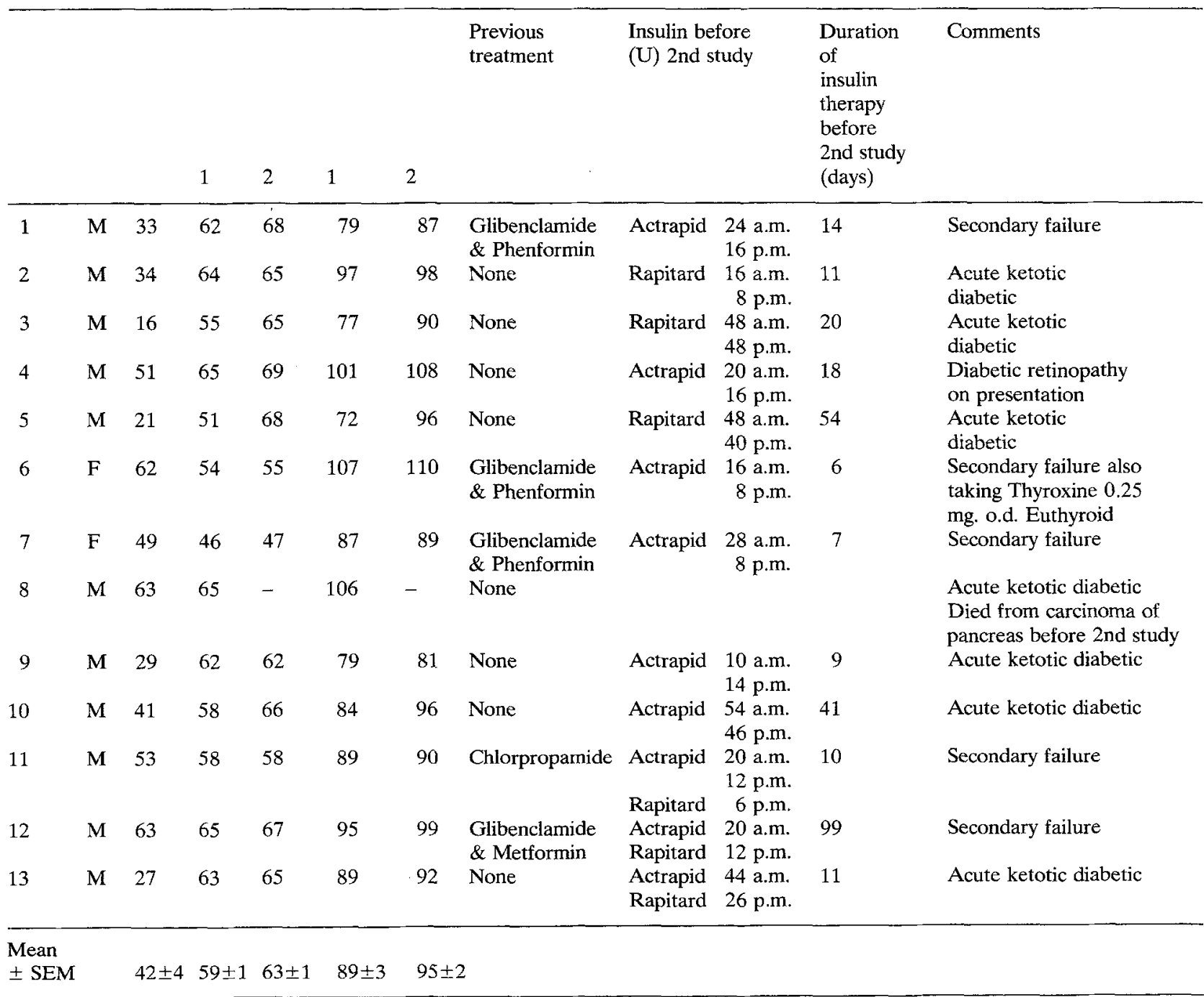


antecubital vein under local anaesthesia and a 30 min rest period, blood was taken for initial hormone and metabolite estimations. Samples for metabolites were mixed with perchloric acid $(4 \mathrm{ml}$ blood plus $4 \mathrm{mI} 10 \%(\mathrm{v} / \mathrm{v})$ perchloric acid) and immediately frozen. Fifty $\mu \mathrm{Ci}$ of ${ }^{14} \mathrm{C}$-l-palmitic acid and $50 \mu \mathrm{Ci}$ of ${ }^{3} \mathrm{H}$-3-glucose (Radiochemical Centre, Amersham, England) were then rapidly injected into a contralateral vein. Glucose tritiated in the 3-position was chosen as it probably gives the best estimate of glucose production in the postabsorptive state [1]. Blood samples were taken over a two hour period starting at one minute and sampling every minute for the first five minutes. Blood was placed into heparinised tubes for free fatty acid (FFA) determinations and into fluoride-oxalate tubes for glucose measurements and centrifuged at $4^{\circ} \mathrm{C}$.

Seven, five minute collections of expired air were made at intervals starting at ten minutes after injection of isotopes. Subjects inspired room air with the inspiratory volume being measured by a Wright respirometer (British Oxygen Company, Essex, England) and expired into a Douglas bag. $R Q$ determination was based on analysis of the last five bags.

During the test, diabetic patients drank 1 to 21 water and a urine collection was made during the test period to assess urinary glucose loss. All subjects made a $24 \mathrm{~h}$ urine collection (to include the test period) so that protein metabolism could be estimated through measurement of urea excretion.

\section{Chemical Methods}

${ }^{14} \mathrm{C}$ - 1 -palmitic acid was combined with $(10 \mathrm{~g} / 100 \mathrm{ml})$ human serum albumin (Lister Institute, Herts., England) by a modification of the method described by Malmendier [2]. After addition of ${ }^{3} \mathrm{H}-3$-glucose, the solution was sterilised by filtration.

Concentration of FFA was measured in $0.5 \mathrm{ml}$ of plasma by the method of Carruthers and Young [3]. For repeated extractions of a single sample the coefficient of variation was $3.0 \%$ and for extractions of duplicate samples $3.1 \%$. Labelled FFA were isolated from $1 \mathrm{ml}$ of plasma by the same method except that the heptane extract was evaporated and redissolved in a toluene based scintillant and counted in a scintillation counter (Intertechnique, Middlesex, England). Further passage of the heptane extract through silicic acid columns [4] produced no appreciable removal of ${ }^{14} \mathrm{C}$ over the thirty minute period that the specific activity of plasma FFA was followed. Plasma and urine glucose concentration were measured enzymically using a Beckman glucose analyser. $\left[{ }^{3} \mathrm{H}\right]$ in glucose was determined from a freeze-dried deproteinised plasma extract [5].

Oxygen concentration in the expired air was measured using an oxygen analyser (Model S3A, Allied Electrochemistry Inc., Sunnyvale, California) calibrated with room air. Carbon dioxide concentration was measured using an infra-red absorption capnograph (Godart NV, Bilthoven, Holland) calibrated with gases containing $2 \%, 4 \%$ and $6 \%$ carbon dioxide. The exact concentration of the calibration gases was determined with the Lloyd-Haldane apparatus.

Urinary urea was determined by the diacetyl monoxime method [6]. Plasma concentrations of insulin and growth hormone were measured by a double antibody technique [7]. Thyroxine $\left(T_{4}\right)$, trïiodothyronine $\left(T_{3}\right)$ and reverse $T_{3}\left(\mathrm{rT}_{3}\right)$ serum concentrations were also measured by radioimmunoassay [8,9]. Acetoacetic acid and 3-hydroxybutyrate were measured enzymically [10]; total ketone bodies were the sum of acetoacetate and 3hydroxybutyrate. Plasma cortisol was measured [11] in samples taken between 9-9.30 a.m. in all subjects.

All $\mathrm{p}$ values were calculated using Student's unpaired $t$ test between normal subjects and patients (ND) and a paired $t$ test between studies in the same subjects $\left(\mathrm{N}_{1} \mathrm{~N}_{2}, \mathrm{D}_{1} \mathrm{D}_{2}\right)$.

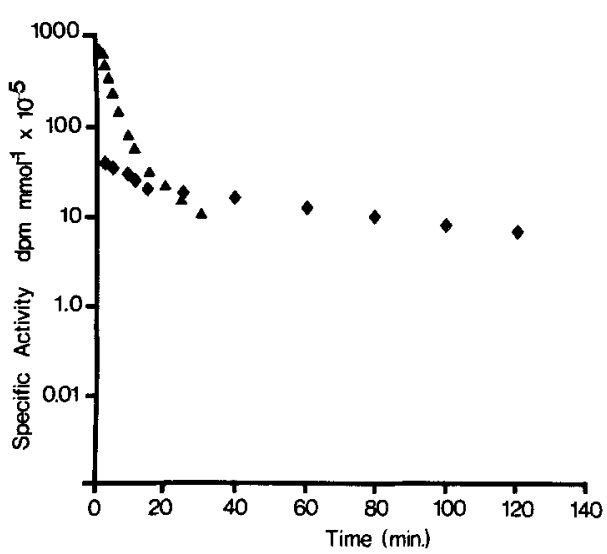

Fig. 1. Plasma specific activity time curves for ${ }^{14} \mathrm{C}-\mathrm{FFA}(\boldsymbol{\Delta})$ and ${ }^{3} \mathrm{H}$-glucose $(\bullet)$ after tracer injection in a normal subject

\section{Calculations}

a) Turnover Rates: The rates of appearance (Ra) of glucose and FFA were determined by tracer injection [12]. In a steady state Ra $=\mathrm{Rd}$ (the rate of disappearance) $=\mathrm{RT}$ (the turnover rate). The form of the equation used was:

$\mathrm{RT}=\int_{0}^{\infty} \frac{\mathrm{M}^{*}}{\mathrm{~S} . \mathrm{A} \cdot \mathrm{dt}}$

Where $\mathbf{M}^{*}=$ the injected dose of tracer (dpm) and S.A. = specific activity.

Double exponential functions were fitted to the specific activity-time curve for ${ }^{14} \mathrm{C}$-FFA and ${ }^{3} \mathrm{H}$-glucose using an iterative program (which also performed the integration) on a Wang $600 \mathrm{com}$ puter.

In fasted diabetic patients, glucose $\mathrm{Rd}$ has two components: the metabolic $R d$ or rate of utilisation $\left(R_{u t}\right)$ and the urinary $R d$. $R_{u t}$ glucose was therefore calculated by subtracting the urinary glucose loss from the isotopically measured total Rd.

Glucose metabolic clearance rate was calculated by dividing the glucose $\mathrm{R}_{\mathrm{ut}}$ by the plasma glucose concentration.

b) Respiratory Exchange: All gas volumes were corrected to standard temperature and pressure. Oxygen consumption and carbon dioxide production $\left(\mathrm{ml} \mathrm{min}^{-1}\right)$ were then calculated. Corrections for protein metabolism were then made from urinary urea excretions [13].

\section{Results}

The specific activity time curves for ${ }^{3} \mathrm{H}$-glucose and ${ }^{14} \mathrm{C}$ FFA in plasma from an experiment in a normal subject are shown in Figure 1. The rates of production $(\mathrm{Ra})$, utilisation $\left(\mathrm{R}_{\mathrm{ut}}\right)$ and metabolic clearance rate (MCR) of glucose in normals and diabetics from both studies appear in Figure 2. Glucose Ra was increased in untreated diabetics $(\mathrm{p}<0.001)$ and fell after insulin, whereas glucose utilisation was more variable in the patient group ( $F$ test, $\mathrm{p}<0.05$ ) with two patients above and below the limits of the normal group. Insulin treatment reduced the variation in $R_{u t}$ 

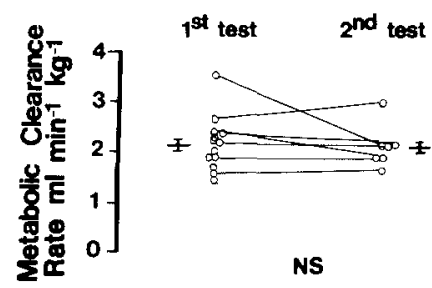

NS

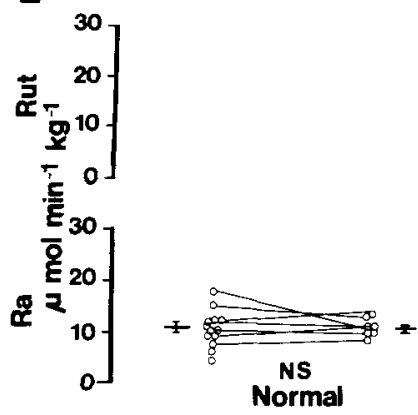

Fig. 2. Glucose metabolic clearance rates, rates of utilisation $\left(R_{u t}\right)$ and rates of appearance $(\mathrm{Ra})$ in normal subjects $(O)$ and diabetic patients, before $(\triangle)$ and after $(\boldsymbol{\Delta})$ insulin. Lines and bars mean $\pm \mathrm{SEM}$. NS - no significant difference. $\mathrm{Ra}=\mathrm{R}_{\mathrm{ut}}$ in normal subjects
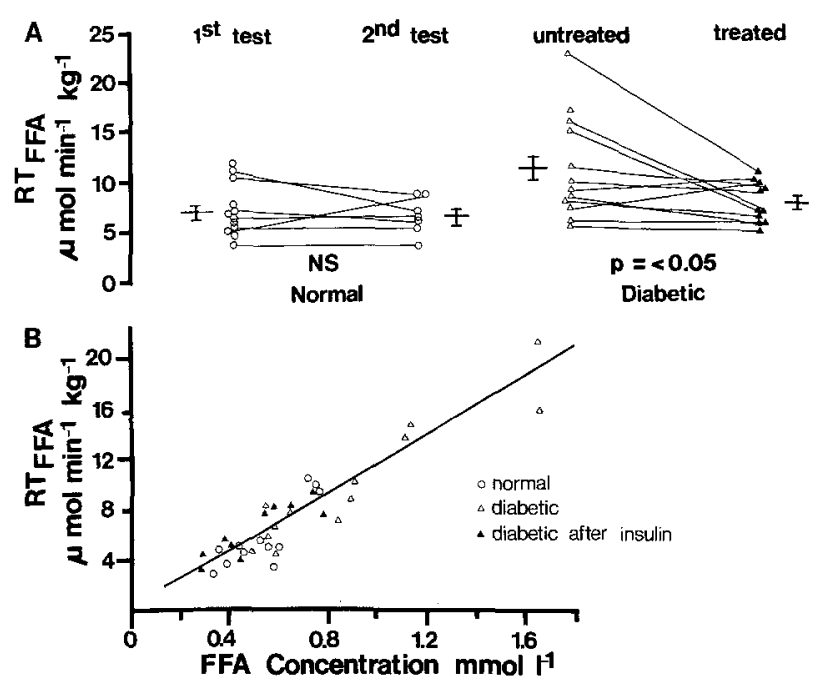

Fig. 4. A Free fatty acid turnover rates $\left(\mathbf{R T}_{\mathrm{FFA}}\right)$ in normal subjects $(O)$ and in diabetic patients before $(\triangle)$ and after $(\Delta)$ insulin. B The relationship between plasma concentration and the turnover rate of FFA in all subjects. (For normal subjects, $r=0.82$, $\mathrm{p}<0.001$; for diabetics $\mathrm{r}=0.93, \mathrm{p}<0.001$ )

between patients but did not alter the mean value. Glucose metabolic clearance rate was markedly decreased in untreated diabetics compared with normal subjects and although increased by insulin was still subnormal.

There was a linear relationship (Fig. 3) between glucose production and plasma glucose concentration in untreated diabetics and in those treated diabetics

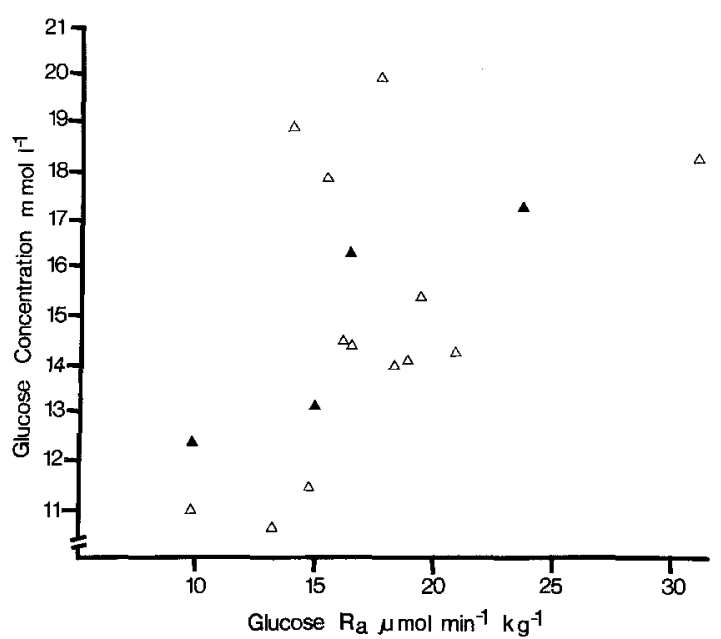

Fig. 3. Relationship between glucose production ( $\mathrm{Ra}$ ) and plasma glucose concentration in diabetic patients before $(\triangle)$ and after (A) insulin $(\mathrm{r}=0.60, \mathrm{p}<0.02)$. Those patients who still had hyperglycaemia $>10 \mathrm{mmol} / 1$ and glycosuria after insulin are included with the pretreatment group. (For untreated diabetics alone $\mathrm{r}=0.54, \mathrm{p}<0.05$ )

whose plasma glucose concentration exceeded $10 \mathrm{mmol} 1^{-1}$. In the normal group plasma glucose concentration only varied from 4.28 to $5.68 \mathrm{mmol} \mathrm{l}^{-1}$

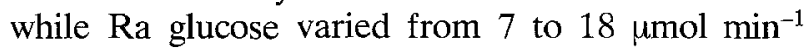
$\mathrm{kg}^{-1}$.

Figure 4 A shows the turnover rates of FFA in all subjects and their change between studies. On average, both concentrations and turnover were higher in diabetics than normal although there were several diabetics who fell within the normal range. Insulin treatment reduced turnover rate and concentration of FFA (Table 2) to normal. FFA turnover was linearly related to concentration (Fig. 4B) and results from both untreated and treated diabetics fell on the same regression line as those from the normal subjects. Figure 5 shows that the turnover rate of FFA and the rate of glucose utilisation were inversely related.

Ketone body concentration was also inversely related to the rate of glucose utilisation $(\mathrm{r}=-0.63$, $\mathrm{p}<0.02$ ). Details of blood metabolite concentrations are given in Table 2. There were no significant changes in the normal subjects between the first and second study. Ketone body concentrations varied considerably between diabetic patients and the mean was considerably greater than normal. Insulin treatment decreased the ketone body concentration in all patients.

Table 3 gives details of plasma hormone concentrations from all studies. Again there were no significant differences between studies in the normal group. 
Insulin and growth hormone concentrations were similar in both groups. On the other hand there were marked differences between normal subjects and diabetic patients in the concentration of cortisol, which was raised, and in the concentration of the thyroid hormones $T_{4}$ and $T_{3}$ which were reduced in untreated diabetics. The average concentration of $\mathrm{rT}_{3}$ was increased nearly threefold in the untreated diabetics and was inversely related to the serum concentration of $\mathrm{T}_{3}(\mathrm{r}=-0.70, \mathrm{p}<0.02)$. When untreated and treated diabetics were considered together cortisol concentration was directly related to the rate of glucose production (Fig. 6) and blood ketone body concentration ( $\mathrm{r}=0.53, \mathrm{p}<0.02$ ). There was a similar relationship between the concentration of $\mathrm{T}_{3}$ and glucose utilisation rate $(\mathrm{r}=0.6$, $\mathrm{p}<0.05$ ) and glucose metabolic clearance rate in untreated diabetics. The latter relationship is shown in Figure 7.

Measurements of respiratory exchange are shown in Table 4. Although average oxygen consumption in diabetics was not significantly different from normal, it was significantly higher in those with elevated plasma FFA and blood ketone bodies. Blood ketone body concentration and its relationship to oxygen consumption are shown in Figure 8. The respiratory quotient varied widely in the untreated diabetic group being directly related to glucose utilisation (Fig. 9). There was a tendency for the respiratory quotient to be lower in patients with high free fatty acid turnover and ketone body concentration but this did not reach statistical significance. The respiratory quotient was inversely related to the combined con- centrations of FFA and ketone bodies $(r=-0.58$, $\mathrm{p}<0.05$ ).

\section{Discussion}

\section{Glucose Metabolism}

Our study confirms that untreated diabetes mellitus is characterised by over-production of glucose [14, 15]. In the face of insulin deficiency and in the absence of normal feedback control, glucose accumulates in the circulation. The rate of glucose production was a major determinant of the degree of hyperglycaemia of the patients both before they were treated and afterwards, if insulin dosage was insuffi-

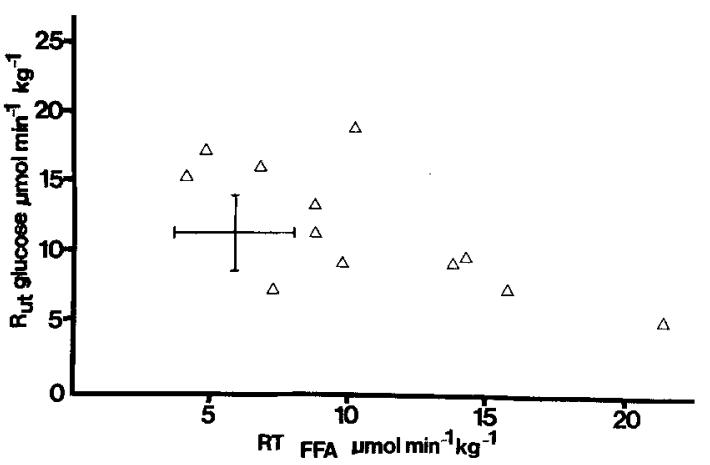

Fig. 5. Relationship between the turnover rate of FFA $\left(\mathrm{RT}_{\mathrm{FFA}}\right)$ and the rate of glucose utilisation $\left(R_{u t}\right)$ in untreated diabetic patients. $(r=0.61, p<0.05)$. The crossed bars show the mean \pm SD for normal subjects. $n=12, R_{u t}$ not available on one patient

Table $2 \mathrm{~A}$ and $\mathbf{B}$. Metabolite concentrations in normal, untreated diabetic and insulin-treated diabetic subjects A Normal (N)

\begin{tabular}{|c|c|c|c|c|c|c|c|c|c|c|c|c|}
\hline \multirow[b]{3}{*}{ Test } & \multirow{2}{*}{\multicolumn{2}{|c|}{ Glucose }} & \multirow{2}{*}{\multicolumn{2}{|c|}{ FFA }} & \multicolumn{6}{|c|}{ Metabolite concentration mmol. $\mathrm{l}^{-1}$} & \multirow{2}{*}{\multicolumn{2}{|c|}{$\begin{array}{l}\text { Total } \\
\text { ketone-bodies }\end{array}$}} \\
\hline & & & & & \multicolumn{2}{|c|}{ Lactate } & \multicolumn{2}{|c|}{ Pyruvate } & \multicolumn{2}{|c|}{ Glycerol } & & \\
\hline & 1 & 2 & 1 & 2 & $\overline{1}$ & 2 & 1 & 2 & 1 & 2 & 1 & 2 \\
\hline Mean & 5.0 & 5.2 & 0.55 & 0.42 & 0.68 & 0.68 & 0.054 & 0.055 & 0.09 & 0.11 & 0.16 & 0.08 \\
\hline SD & 0.5 & 0.5 & 0.15 & 0.15 & 0.24 & 0.13 & 0.021 & 0.014 & 0.06 & 0.08 & 0.11 & 0.03 \\
\hline $\mathbf{n}$ & 13 & 7 & 12 & 7 & 13 & 7 & 13 & 7 & 13 & 7 & 13 & 7 \\
\hline
\end{tabular}

B Diabetic (D)

\begin{tabular}{lllllllllllll}
\hline Test & 1 & 2 & 1 & 2 & 1 & 2 & 1 & 2 & 1 & 2 & 1 & 2 \\
\hline Mean & 15.1 & 10.2 & 0.91 & 0.57 & 0.86 & 0.79 & 0.050 & 0.058 & 0.14 & 0.13 & 2.72 & 0.21 \\
$\mathrm{SD}$ & 3.0 & 4.1 & 0.40 & 0.24 & 0.43 & 0.29 & 0.014 & 0.017 & 0.09 & 0.10 & 2.87 & 0.14 \\
$\mathrm{n}$ & 13 & 12 & 13 & 12 & 13 & 10 & 13 & 10 & 13 & 10 & 13 & 10 \\
$\mathrm{D}_{1} \mathrm{D}_{2}$ & $\mathrm{p}=<0.001$ & $\mathrm{p}=<0.025$ & & $*$ & & $*$ & & & $*$ & $\mathrm{p}=<0.02$ \\
$\mathrm{~N}_{1} \mathrm{D}_{1}$ & $\mathrm{p}=<0.001$ & $\mathrm{p}=<0.025$ & & $*$ & & $*$ & & & $*$ & $\mathrm{p}=<0.01$ \\
$\mathrm{~N}_{1} \mathrm{D}_{2}$ & $\mathrm{p}=<0.01$ & & $*$ & & $*$ & & $*$ & & & $*$ & & $*$
\end{tabular}

The suffixes 1 and 2 denote the first and second studies; thus $D_{1} D_{2}$ refers to the statistical comparison between the first and second studies in diabetic patients. $*=$ not significant 
Table $3 \mathrm{~A}$ and B. Hormone concentrations in normal, untreated diabetic and insulin-treated diabetic subjects A Normal (N)

\begin{tabular}{|c|c|c|c|c|c|c|c|c|c|c|c|c|}
\hline & \multirow{2}{*}{\multicolumn{2}{|c|}{$\begin{array}{l}\text { Insulin } \\
\mu \mathrm{U} \cdot \mathrm{ml}^{-1}\end{array}$}} & \multirow{2}{*}{\multicolumn{2}{|c|}{$\begin{array}{l}\text { Growth } \\
\text { hormone } \\
\text { ng. } \mathrm{ml}^{-1}\end{array}$}} & \multicolumn{8}{|c|}{ Fasting hormone concentrations } \\
\hline & & & & & \multicolumn{2}{|c|}{$\begin{array}{l}\text { Cortisol } \\
\text { nmol.1 }^{-1}\end{array}$} & \multicolumn{2}{|c|}{$\begin{array}{l}\mathrm{T}_{4} \\
\text { nmol.1 }^{-1}\end{array}$} & \multicolumn{2}{|c|}{$\begin{array}{l}\mathrm{T}_{3} \\
\text { nmol. }^{-1}\end{array}$} & \multicolumn{2}{|c|}{$\begin{array}{l}\mathrm{rT}_{3} \\
\mathrm{nmol}^{-1} \mathrm{l}^{-1}\end{array}$} \\
\hline & 1 & 2 & 1 & 2 & $\overline{1}$ & 2 & $\overline{1}$ & $\overline{2}$ & $\overline{1}$ & 2 & 1 & 2 \\
\hline Mean & 4.3 & 3.2 & 4.0 & 1.8 & 242 & 232 & 87 & 83 & 1.64 & 1.56 & 0.17 & 0.17 \\
\hline SD & 2.7 & 2.1 & 6.1 & 3.3 & 59 & 103 & 17 & 28 & 0.29 & 0.29 & 0.13 & 0.16 \\
\hline $\mathrm{n}$ & 13 & 7 & 13 & 7 & 12 & 7 & 13 & 7 & 12 & 3 & 13 & 7 \\
\hline
\end{tabular}

B Diabetic (D)

\begin{tabular}{lcccccccccccc}
\hline \multicolumn{1}{c}{1} & 2 & 1 & 2 & 1 & 2 & 1 & 2 & 1 & 2 & 1 & 2 \\
\hline Mean & 3.9 & 5.3 & 3.0 & 4.6 & 457 & 219 & 72 & 81 & 0.85 & 1.66 & 0.50 & 0.21 \\
$\mathrm{SD}$ & 2.9 & 3.6 & 2.4 & 8.5 & 238 & 84 & 20 & 15 & 0.39 & 0.48 & 0.38 & 0.11 \\
$\mathrm{n}$ & 13 & 12 & 13 & 12 & 13 & 12 & 12 & 11 & 12 & 11 & 12 & 11 \\
$\mathrm{D}_{1} \mathrm{D}_{2}$ & $*$ & & $*$ & & $\mathrm{p}=<0.001$ & $\mathrm{p}=<0.01$ & $\mathrm{p}=<0.01$ & $\mathrm{p}=<0.05$ \\
$\mathrm{~N}_{1} \mathrm{D}_{1}$ & $*$ & & $*$ & & $\mathrm{p}=<0.01$ & $\mathrm{p}=<0.02$ & $\mathrm{p}=<0.001$ & $\mathrm{p}=<0.002$ \\
\hline
\end{tabular}

Thyroid hormone results from patient 6 omitted. Symbols as in Table 2

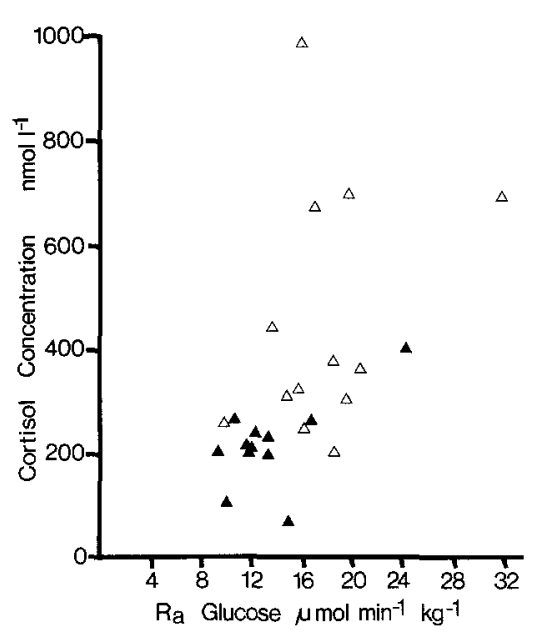

Fig. 6. Relationship between cortisol concentration and glucose production in diabetic patients before insulin $(\triangle)$ and after insulin (A). $(\mathrm{r}=0.50, \mathrm{p}<0.02)$

cient or of too short activity to lower fasting blood glucose below $10 \mathrm{mmol} / 1$ and prevent glycosuria. (Fig. 3). The lower metabolic clearance rate of glucose was obviously also a contributing factor. The rate of glucose uptake varied considerably between patients. Glycosuria accounted for as much as $60 \%$ of the total glucose production in ketotic patients (ketone body concentration $>2 \mathrm{mmol} \mathrm{l}^{-1}$ ). In contrast, non-ketotic subjects showed normal or even increased rates of glucose utilisation which fell on treatment; indicating perhaps that hyperglycaemia in these subjects may have increased peripheral glucose

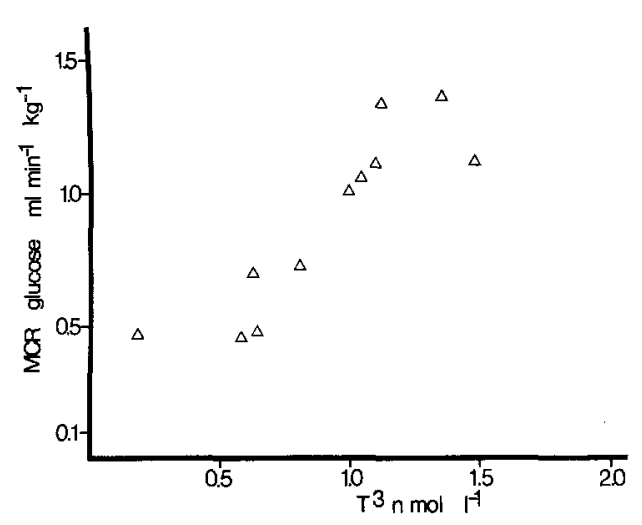

Fig. 7. Relationship between serum $T_{3}$ concentration and the metabolic clearance rates of glucose in diabetic patients before insulin treatment $(r=0.90, p<0.001) . n=11$

uptake by a mass action effect $[16,17]$. Bowen and Moorhouse [14] noted similar high rates of glucose utilisation in maturity onset diabetics and concluded from measurement of ${ }^{14} \mathrm{CO}_{2}$ exhaled that much of this glucose was neither oxidised nor excreted. From our study it appeared that there was indeed a group of diabetics whose tissues had a high rate of glucose uptake, but the relationship between the RQ and the rate of glucose uptake leads us to believe that much of this glucose was oxidised.

It is interesting to note that the three patients with the highest rates of glucose utilisation and 
respiratory quotients (Fig. 9) were about to be started on insulin because of an inadequate response to sulphonylureas. They were not ketosis prone and possibly represent the type of patient most susceptible to hyperosmolar non-ketotic coma.

Although it is generally accepted that cellular glucose deprivation is characteristic of diabetes, some patients had near normal rates of glucose utilisation. However, even if the total rate of glucose utilisation remains unchanged, the relative contribution to the overall glucose uptake by individual organs in the body may be expected to change in the absence of insulin.

Most interestingly, we found the $\mathrm{T}_{3}$ concentration to be closely related to the rate of utilisation and the metabolic clearance rate of glucose (Fig. 7). The significance of thyroid hormone concentrations in diabetes has been discussed elscwhere [8]. If normal $\mathrm{T}_{4} \rightarrow \mathrm{T}_{3}$ conversion depends on glucose and insulin, as recent in vitro work suggests [18], then $\mathrm{T}_{3}$ concentration in diabetics may give a useful indication of the amount of insulin at the receptor site which is facilitating glucose uptake.

We found that the most noticeable and consistent effect of insulin treatment was its restraining effect on hepatic glucose production. Its effect on glucose utilisation was less marked, although glucose removal became more efficient after treatment as reflected in the rise of the metabolic clearance rate of glucose.

Much higher levels of insulin are required to stimulate entry of glucose into tissues than are needed to reduce hepatic glucose production [19]. As many of our patients were still hyperglycaemic after insulin it is likely that their tissues were exposed to low levels of insulin at that time. Thus it is expected that the hepatic action of insulin would predominate over its effect on glucose utilisation.

\section{Free Fatty Acid Metabolism}

As $20-30 \%$ of FFA leaving the plasma is rapidly returned to it [20], the flux rate calculated from our isotopic data probably represents the rate of irreversible removal of FFA and may underestimate their actual rate of release. Our values for normal subjects are similar to those of Waterhouse et al. [21] and the rates of total FFA transport found by Eaton et al. [20]. The linear relationship between the plasma concentration and the respective turnover rates of both main products of triglyceride metabolism, glycerol and FFA, in animals and normal man is well known $[22,23,24,25]$.

The fall in FFA concentration and turnover following insulin treatment confirms the findings of other workers [25] and demonstrates that in vivo as
Table $4 \mathrm{~A}$ and B. Respiratory exchange A Normal (N)

\begin{tabular}{|c|c|c|c|c|}
\hline \multirow[b]{2}{*}{ Test } & \multicolumn{2}{|c|}{$\begin{array}{l}\text { Protein corrected } \\
\text { oxygen consumption } \\
\text { ml.min }{ }^{-1} \cdot \mathrm{kg}^{-1}\end{array}$} & \multicolumn{2}{|l|}{$\mathrm{RQ}$} \\
\hline & 1 & 2 & $\overline{1}$ & 2 \\
\hline Mean & 2.95 & 2.48 & 0.727 & 0.809 \\
\hline SD & 0.37 & 0.27 & 0.069 & 0.088 \\
\hline $\mathrm{n}$ & 13 & 7 & 13 & 7 \\
\hline
\end{tabular}

B Diabetic (D)

\begin{tabular}{|c|c|c|c|c|}
\hline Test & 1 & 2 & 1 & 2 \\
\hline Mean & 3.32 & 3.10 & 0.762 & 0.861 \\
\hline SD & 0.76 & 0.69 & 0.182 & 0.127 \\
\hline $\mathrm{n}$ & 13 & 12 & 13 & 12 \\
\hline $\mathrm{D}_{1} \mathrm{D}_{2}$ & \multicolumn{2}{|c|}{$*$} & \multicolumn{2}{|c|}{$\mathrm{p}=<0.05$} \\
\hline
\end{tabular}

Symbols as in Table 2

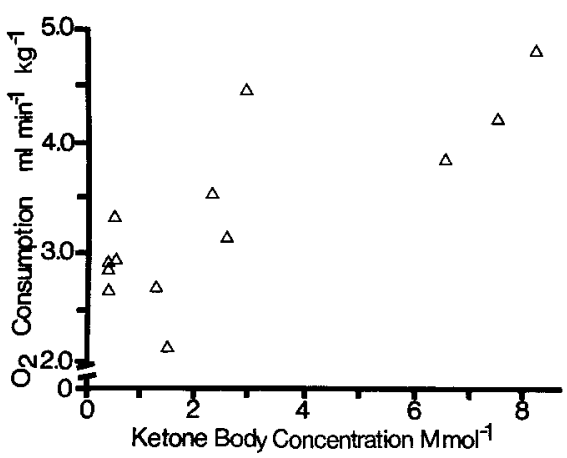

Fig. 8. Plasma ketone body concentration and oxygen consumption in diabetic patients before insulin treatment $(r=0.78$, $\mathrm{p}<0.01$ )

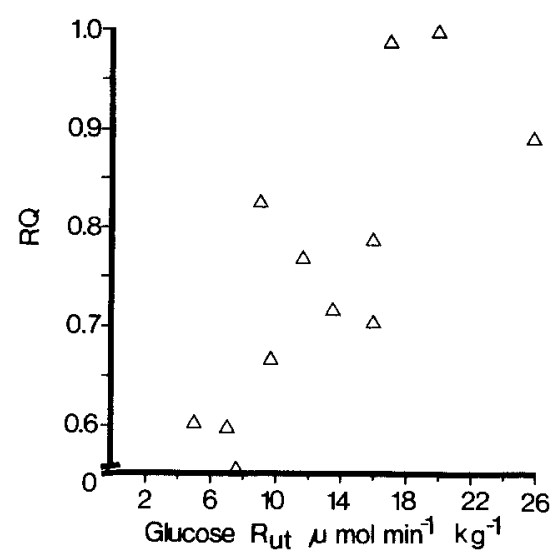

Fig. 9. The rate of glucose utilisation $\left(R_{u t}\right)$ and the respiratory quotient $(\mathrm{RQ})$ in diabctic patients before insulin treatment $(\mathrm{r}=$ $0.75, \mathrm{p}<0.01$ ) 
well as in vitro, this fall is brought about by reducing lipolysis.

\section{Relationship between FFA and Glucose Metabolism}

The finding of an inverse relationship between the rate of utilisation of glucose and free fatty acids (and ketone bodies) is a direct demonstration of reciprocity between these substrates in the untreated diabetic patient. This inter-relationship is complex and is regulated by several factors. Thus increasing the supply of glucose to adipose tissue in vivo would be expected to increase re-esterification of FFA, thereby limiting their release [26] and hence their availability to muscle. On the other hand, in vitro experiments have shown that glucose utilisation is impaired in muscle by the accumulation of intermediates of fatty acid metabolism. These metabolites inhibit various steps of glycolysis and lead to a decrease in glucose phosphorylation $[27,28]$. On the basis of such evidence obtained in vitro, Randle et al have suggested that these mechanisms are physiological regulators of "energy metabolism" in vivo [27].

In the normal adult under the powerful over-riding influence of insulin the importance of such a mode of regulation is doubtful, but it could be argued that in diabetes, in the absence of normal control, "energy metabolism" will be regulated by these basic peripheral mechanisms. So far attempts to demonstrate in vivo, that reciprocal inhibition of utilisation of glucose and FFA is important in regulating substrate metabolism, have been complicated by endogenous insulin secretion.

In this study the inverse relationship found between the rates of metabolism of glucose and FFA in our patients before treatment may well have reflected the change from hormonal to a more primitive cellular metabolic regulation after the collapse of homeostasis.

\section{Involvement of hGH, Cortisol and Glucagon}

It has been reported that hGH levels are elevated in uncontrolled diabetics [29] and Luft et al. [30] demonstrated that hGH is ketogenic when given to hypophysectomised diabetics. We were unable to find any correlation between hGH and any of the measured variables. This is not surprising in view of the pulsatile secretion and delayed metabolic action of $h \mathrm{hH}$.

The catabolic state induced by insulin lack was further compounded by the diabetogenic effects of high levels of cortisol. Cortisol secretion rates are abnormally high in uncontrolled diabetes as in other stressful illnesses [31]. However, in the absence of its normal insulinogenic effect hepatic glucose production rose in the diabetic as the cortisol concentration increased.

\section{Energy Balance}

It is frequently stated that if all FFA removed from the plasma were completely oxidised, this would yield sufficient calories to meet or exceed energy demands. In our normal subjects, the mean disappearance rate of FFA was $2.16 \mathrm{~g} \mathrm{FFA} \mathrm{day}^{-1} \mathrm{~kg}^{-1}$ which, if completely oxidised, would provide $20 \mathrm{kcal}$ day $^{-1} \mathrm{~kg}^{-1}$. This was approximately equal to the basal metabolic rate of $20.5 \mathrm{kcal} \mathrm{day}^{-1} \mathrm{~kg}^{-1}$ calculated from the RQ and the oxygen consumption using the table of Lusk [13]. Therefore it is improbable that all FFA removed from the circulation during the course of the experiment were immediately oxidised.

Since respiratory exchange was measured simultaneously with glucose and FFA turnover, it is possible to calculate the FFA oxidation rate without reference to turnover measurements. One gram of palmitic acid requires 2.0 litres of oxygen for its complete combustion and produces 1.4 litres of carbon dioxide; one gram of glucose requires 0.80 litres of oxygen, producing the same volume of carbon dioxide. Using the results from all experiments on normal subjects the mean measured non-protein oxygen consumption was 4.021 day $^{-1} \mathrm{~kg}^{-1}$ and carbon dioxide production was 3.031 day $^{-1} \mathrm{~kg}^{-1}$.

Thus, $4.02=2.0 \times$ fat oxidised $+0.8 \times$ car $^{-}$ bohydrate oxidised; and $3.03=1.4 \times$ fat oxidised $+0.8 \times$ carbohydrate oxidised. Solving these equations, $1.65 \mathrm{~g}$ fat, day ${ }^{-1} \mathrm{~kg}^{-1}$ were oxidised, equivalent to $75 \%$ of the turnover rate of FFA. It seems likely that the proportion of FFA unaccounted for accumulates in slowly turning over lipid pools such as those of muscle [32] or hepatic and adipose tissue triglyceride.

Glucose oxidation may also be estimated from the respiratory exchange by the above equations. By this calculation, 0.96 g glucose day ${ }^{-1} \mathrm{~kg}^{-1}$ were oxidised. This is considerably less than the $2.97 \mathrm{~g}$ day $^{-1}$ $\mathrm{kg}^{-1}$ calculated from the glucose turnover. This suggests that a major part of glucose produced by the liver is not oxidised.

\section{Conclusions}

There are of course differing indications for insulin therapy: thus acute juvenile-onset ketotic diabetes with a florid and classical symptomatology (as for 
example in case D3) presents different metabolic features from those seen in older patients with so called "secondary failure" in whom oral agents have failed to control hyperglycaemia (for example D6).

There was however, a continuous spectrum of metabolic abnormalities discernible within this group of insulin-requiring patients - notably in the reciprocal relationship found between the rates of utilisation of the two main energy providing substrates glucose and FFA. The overall energy expenditures of diabetics and normals are equal but the ratio of calories provided by FFA versus those derived from glucose varied considerably within the untreated patients. This finding suggests that in diabetes the glucose: fatty acid cycle may well be an important regulatory factor in "energy" metabolism.

Hyperglycaemia in diabetes has long been attributed solely to a decreased rate of glucose utilisation or lowered MCR of glucose. In this study neither of these variables could account for the observed hyperglycaemia, and overproduction of glucose appeared to be a major contributing factor.

Acknowledgements. We are grateful to Drs. R. Edwards, B. Brown and Ms. H. Mather from the Middlesex Hospital, London, for the measurement of thyroid hormones. We would also like to thank Dr. R. McSwiney for the measurement of urinary urea; Drs. I. R. Cameron and J. Lyall for their loan of gas analysing equipment, Mrs. R. Miller for measurement of standard gases and Miss A. Halliman for sterilising injection solutions. We also gratefully acknowledge expert technical assistance from Misses Hillary Quine, Leonie Sachs and Sandra Juul and the secretarial assistance of Mrs. J. Buzza, Mrs. J. Wisher and Mrs. J. Seyfried. We are also indebted to Dr. G. Hetenyi, Jr. for reading the manuscript and for his helpful comments.

This work was supported by a grant from St. Thomas's Hospital Endowments Committee and the British Diabetic Association. Dr. S. E. H. Hall was a recipient of a Fellowship from the Medical Research Council of Canada.

\section{References}

1. Altzuler, N. A., Barkai, C., Bjerknes, C., Gottlieb, B., Steele, R.: Glucose turnover values in the dog obtained with various species of labelled glucose. Am. J. Physiol. 229, 1662-1667 (1975)

2. Malmendier, C., Delcroix, C., Berman, M.: Interrelations in the oxidative metabolism of FFA, glucose and glycerol in normal and hyperlipaemic patients. J. Clin. Invest. 54, 461-472 (1974)

3. Carruthers, M., Young, D. A. B.: FFA estimation by a semiautomated fluorimetric method. Clin. Chim. Acta 49, 341-348 (1973)

4. McCarthy, R. D., Duthie, A. H.: A rapid quantitative method for the separation of free fatty acids from other lipids. J. Lipid Res. 3, 117-119 (1962)

5. Somogyi, M.: Determination of blood sugar. J. Biol. Chem. 160, 69-73 (1945)

6. Natelson, S., Scott, M. L., Beff, C.: A rapid method for the estimation of urea in biologic fluids. Am. J. Clin. Pathol. 21 , 275-281 (1951)

7. Sönksen, P. H.: Double antibody technique for the simultaneous assay of insulin and growth hormones. In: Hormones in human blood: detection and assay. Antoniades, H. A. (Ed), pp 176-199. Cambridge, Mass., London: Harvard University Press 1976

8. Saunders, J., Hall, S. E. H., Sönksen, P. H.: Thyroid hormones in insulin requiring diabetes before and after treatment. Diabetologia 15, 29-32 (1978)

9. Meinhold, H., Wenzel, K.W., Schürnbrand, P.: Radioimmunoassay of $3,3^{\prime}, 5^{\prime}$-triiodo-L-thyronine (reverse T3) in human serum and its application in different thyroid states. $Z$. Klin. Chem. Klin. Biochem. 13, 571-574 (1975)

10. Williamson, D. H., Mellanby, J., Krebs, H. A.: Enzymic determination of $\mathrm{D}(-)$ hydroxybutyric acid and acetoacetic acid in blood. Biochem. J. 82, 90-96 (1962)

11. Vermeulen, S.: Estimation of steroid hormones in blood by competitive protein binding. In: Hormones in human blood: detection and assay. Antoniade, H. A. (Ed.), pp 720-750. Cambridge, Mass., London: Harvard University Press 1976

12. Hetenyi, G., Jr., Norwich, K. H.: Validity of the rates of production and utilization of metabolites as determined by tracer methods in intact animals. Fed. Proc. 33, 1841-1848 (1974)

13. Peters, J. P., Van Slyke, D. D.: Quantitative clinical chemistry, pp 6-10. London: Balliere, Tindall and Cox 1931

14. Bowen, H.F., Moorhouse, J. A.: Glucose turnover and disposal in maturity onset diabetes. J. Clin. Invest. 52, 303-319 (1973)

15. Forbath, N., Hetenyi, Jr., G.: Glucose dynamics in normal subjects and diabetic patients before and after a glucose load. Diabetes 15, 778-789 (1964)

16. Soskin, S., Levine, R.: A relationship between the blood sugar levels and the rate of sugar utilization, affecting the theories of diabetes. Am. J. Physiol. 120, 761-770 (1937)

17. Hales, C. N.: Some actions of hormones in the regulation of glucose metabolism. Essays Biochem. 2, 383-388 (1963)

18. Balsam, A., Ingram, S. H.: The influence of fasting, diabetes and several pharmacological agents on the pathways of thyroxine metabolism in rat liver. J. Clin. Invest. 62, 415-424 (1978)

19. Brown, P.M., Tompkins, C. V., Juul, S., Sönksen, P.H.: Mechanism of action of insulin in diabetic patients: a doserelated effect on glucose production and utilisation. Br. Med. J. 1978 I, 1239-1242

20. Eaton, R. P., Berman, M., Steinberg, D.: Kinetic studies of plasma FFA and triglyceride metabolism in man. J. Clin. Invest. 48, 1560-1579 (1969)

21. Waterhouse, C., Baker, N., Rostanis, H.: Effects of glucose ingestion on the metabolism of free fatty acids in human subjects. J. Lipid Res. 10, 487-494 (1969)

22. Issekutz, B., Bortz, W. M., Miller, H. I., Paul, P.: Turnover of plasma FFA in humans and dogs. Metabolism 16, 1001-1009 (1967)

23. Armstrong, D. T., Steele, R., Altzuler, N., Dunn, A., Bishop, J. S., de Bodo, R. C.: Regulation of plasma free fatty acid turnover. Am. J. Physiol. 210, 9-15 (1961)

24. Bortz, W. P., Paul, P., Haft, A. C., Homes, W. L.: Glycerol turnover and oxidation in man. J. Clin. Invest. 51, 1537-1546 (1972)

25. Lewis, B., Mancini, M., Mattock, M., Chait, A., Fraser, T. R.: Plasma triglyceride and fatty acid metabolism in diabetes mellitus. Eur. J. Clin. Invest. 2, 445-453 (1972)

26. White, J. E., Engel, F. L.: A lipolytic action of epinephrine and norepinephrine on rat adipose tissue in vitro. Proc. Soc. Exp. Biol. Med. 99, 375-378 (1958)

27. Randle, P. J., Hales, C. N., Garland, P. B., Newsholme, E. A. 
The glucose fatty acid cycle. Its role in insulin sensitivity and the metabolic disturbance of diabetes mellitus. Lancet $1963 \mathrm{I}$, 785-789

28. Shipp, J. C.: Interrelation between carbohydrate and fatty acid metabolism of isolated perfused rat heart. Metabolism 13, 852-867 (1964)

29. Alberti, K. G., Hockaday, T. D.: Diabetic coma: serum growth hormone before and during treatment. Diabetologia 2, 13-19 (1973)

30. Luft, R., Cerasi, E.: The effect of human growth hormone on insulin production in panhypopituitarism. Lancet 1964 II, 124-126

31. Jacobs, H. S., Nabarro, J. D. N.: Plasma ll-hydroxy corticosteroid and growth hormone levels in acute medical illness. $\mathrm{Br}$. Med. J. 1969 II, 595-598
32. Dagenais, G. R., Tancredi, R. G., Zierler, K. L.: Free fatty acid oxidation by forearm muscle at rest and evidence for an intramuscular lipid pool in human forearm. J. Clin. Invest. 58, 421-431 (1976)

Received: June 15, 1978,

and in revised form: January 19, 1979

Dr. S. E. H. Hall

Division of Metabolism and Endocrinology

Ottawa Civic Hospital

Carling Ave.

Ottawa, Ontario

Canada 